\title{
Protease exógena em dietas para juvenis de tucunaré-paca (Cichla sp.)
} \author{
Emerson Carlos Soares ${ }^{1}$, Manoel Pereira Filho $^{2}$, Rodrigo Roubach ${ }^{2}$, Renato Carlos Soares e Silva ${ }^{2}$ \\ ${ }^{1}$ Universidade Federal de Alagoas/UFAL, Campus Arapiraca - Pólo Penedo/Engenharia de Pesca. Av. Beira Rio, s/nº, Centro Histórico - \\ Penedo/AL, CEP: 57200-000. \\ 2 Instituto Nacional de Pesquisas da Amazônia/INPA.
}

RESUMO - Neste experimento foi analisada a atividade enzimática da protease exógena nos tratos digestórios dos peixes e, posteriormente, o desempenho zootécnico dos juvenis de tucunaré-paca (Cichla sp.) por intermédio da inclusão de três níveis de protease exógena na dieta com $40 \%$ proteína bruta mais a dieta controle. Para avaliar o melhor nível de inclusão de enzimas, foram elaboradas quatro dietas em forma de peletes com quatro níveis de inclusão de protease exógena $(0,00 ; 0,05 ; 0,10$ e $0,15 \%$ ), em um delineamento inteiramente casualisado (fatorial $4 \times 4$ ). Os melhores resultados de ganho de peso, conversão alimentar e crescimento específico em peso foram apresentados pelos animais alimentados com a dieta contendo $0,10 \%$ de protease exógena. Concluiu-se que a enzima protease exógena adicionada à dieta influenciou os parâmetros corpóreos dos juvenis de tucunaré-paca.

Palavras-chave: alimentação, enzimas, protease exógena, tucunaré

\section{Exogenous protease in diets for tucunaré paca (Cichla sp.) juvenile}

\begin{abstract}
This experiment analyzed the enzymatic activity of the exogenous protease in the fish digestive tract and, afterwards, it was also evaluated the growth performance of tucunaré paca (Cichla sp.) juvenile by the addition of four exogenous protease levels to a control diet with $40 \% \mathrm{CP}$. To evaluate the best enzyme inclusion level, four pelleted diets were elaborated with the following exogenous protease levels $(0.00,0.05,0.10$ and $0.15 \%)$, in a completely randomized design in a $4 \times 4$ factorial arrangement. The best results of average weight gain, feed conversion ratio, and weight specific growth rate were showed by the animals fed with diet containing $0.10 \%$ of exogenous protease. The exogenous protease enzyme added to the diet affected the body characteristics of tucunaré paca juvenile.
\end{abstract}

Key Words: diet, enzymes, exogenous protease, tucunaré

\section{Introdução}

A piscicultura é uma atividade rentável e uma medida eficiente de preservação quando acompanhada de técnicas adequadas de manejo alimentar, de uso da água e de conhecimentos sobre a biologia da espécie alvo do cultivo (Garutti, 2003). As técnicas de cultivo ainda são pouco difundidas e poucos sabem usufruir os conhecimentos gerados pelo avanço das pesquisas no campo da piscicultura. O potencial aquícola no Brasil e, em particular, na região Amazônica favorece a difusão desta atividade, em razão do enorme potencial de recursos hídricos, elevado número da ictiofauna da região e domínio crescente do manejo, principalmente, para peixes carnívoros (FAO, 2002). Apesar destes fatores induzirem ao desenvolvimento da piscicultura regional, este tipo de atividade na Amazônia necessita de incentivos e ainda encontra-se em estádio embrionário quando relacionados a outras regiões do país (FAO, 2002), carecendo de tecnologia e conhecimentos nutricionais para desempenhar importante papel no desenvolvimento sustentável regional.

Intensificar o cultivo está intimamente correlacionado à quantidade de biomassa produzida por área, que pode ser obtido por intermédio do fornecimento de alimento nutricionalmente balanceado. Sabe-se que os gastos com alimentação representam até $80 \%$ dos custos operacionais (Kubtiza, 1999) - fator preponderante para administração dos cultivos atuais.

A elaboração de uma dieta balanceada, especialmente para espécies carnívoras, depende do grande aporte de ingredientes de origem animal (farinha de peixe, por exemplo). No entanto, a farinha de peixe está cada vez mais escassa no mercado, pois tem rendimento abaixo do esperado quando o pescado é transformado neste insumo, assim, a produção 
de um alimento de qualidade nutricional que favoreça o preço final do pescado advindo de cultivo dependerá de novas tecnologias e do uso de ingredientes atrativos mais baratos que forneçam resultados satisfatórios (Pezzato, 1995; Francis et al., 2001).

É comum encontrar alimentos protéicos contendo fatores anti-nutricionais e de baixa digestibilidade (Charlton, 1996). Embora a indústria tente eliminar estes fatores por meio de tratamento térmico, ainda são encontrados elevados níveis de ingredientes inibidores de proteases, principalmente no farelo de soja. No entanto, Sheppy (2001) observou que o uso de protease adicionadas em dietas elimina fatores antinutricionais existentes.

A introdução de atrativos enzimáticos é uma técnica moderna com a finalidade de complementar as enzimas produzidas pelo próprio animal em quantidades insuficientes. Estudos realizados recentemente demonstraram resultados promissores quanto ao aumento de ingredientes vegetais com a complementação enzimática na dieta de frangos, coelhos e peixes (Toral et al., 2002). Segundo Cavero (2004), o uso de protease exógena adicionada à ração influenciou positivamente o desempenho zootécnico do pirarucu.

Embora complexos enzimáticos sejam usados em larga escala na indústria alimentícia, para facilitar a digestibilidade e melhorar o sabor e o valor nutricional dos alimentos (Fungaro \& Mackheroni Jr., 2002), com exceção de alguns poucos estudos, a literatura referindo-se à introdução de protease exógena em rações para peixes ainda é incipiente. São necessárias mais pesquisas para o aprimoramento de rações balanceadas que beneficiem o desenvolvimento de espécies carnívoras, como o tucunaré, em cultivo intensivo.

Podem ser feitas avaliações sobre a utilização de fontes alternativas de alimento, por intermédio do uso de enzimas digestivas exógenas na ração, e relacioná-las com o desempenho zootécnico da espécie, melhorando o aproveitamento de componentes da dieta. Objetivou-se com este trabalho avaliar a atividade enzimática no trato digestório de juvenis de tucunaré e demonstrar o efeito do melhor nível de protease exógena sobre o aproveitamento dos nutrientes de uma dieta elaborada com ingredientes de origem vegetal, por meio do desempenho de juvenis de tucunaré.

\section{Material e Métodos}

Este trabalho foi conduzido na Coordenação de Pesquisas em Aqüicultura (CPAQ) do Instituto Nacional de Pesquisas da Amazônia (INPA), no período de 24 de maio a 9 de agosto de 2004 .
O experimento inicial (12 dias) serviu para analisar a ação da enzima protease endógena sobre determinadas condições de $\mathrm{pH}$, temperatura, substrato e tempo em juvenis de tucunaré.

Foram sacrificados 10 juvenis de tucunaré por dia (totalizando 100 amostras), por meio de choque térmico em processo de treinamento alimentar. Cada peixe foi necropsiado e o trato digestório, coletado, identificado, separado em estômago, para protease ácida, intestino e cecos pilóricos, para protease alcalina, embalado individualmente em recipientes próprios e conservado a $-20^{\circ} \mathrm{C}$ até o momento das análises laboratoriais. Cada porção foi homogeneizada em tampão fosfato (10mM)-tris (20mM)/ glicerina a $4^{\circ} \mathrm{C}$ e separado o sobrenadante.

Para a atividade proteolítica, utilizou-se caseína 1\% como solução de substrato da reação e para análise de pH ácido e pH alcalino, $1 \mathrm{~mL}$ de tampão glicina/HCL $0.1 \mathrm{M}$ e $1 \mathrm{~mL}$ de tampão tris-HCL $0,1 \mathrm{M}$, respectivamente. Para determinar a concentração da enzima in vitro, foi necessário o uso de enzimas endógenas provenientes da homogeneização dos tecidos celulares. Logo após, a mistura foi incubada e, posteriormente, interrompida pela colocação de $250 \mu \mathrm{L}$ de ácido tricloroacético (TCA) a $8 \%$ e centrifugado a $3.000 \mathrm{~g}$, em intervalo de 10 minutos.

A identificação da atividade enzimática dos extratos obtidos dos tratos digestivos dos juvenis de tucunaré, expressos em UI/mg de proteína, foi determinada por espectrofotometria $(280 \mathrm{Nm})$. A tirosina foi usada como padrão e definida como o quantitativo de enzima necessário para catalisar a formação de $1 \mu \mathrm{g}$ de tirosina por minuto (Worthington Enzyme Manual, 1982).

A enzima exógena (protease) foi obtida a partir do fungo Aspergillus oryzae (Alltech do Brasil- 409/103 lote:02-ls174).

As dietas (Tabela 1) foram elaboradas em forma de peletes com quatro níveis de proteases exógenas $(0,0 ; 0,05$; $0,1$ e $0,15 \%)$.

O experimento (55 dias) foi avaliado segundo delineamento experimental inteiramente casualizado com quatro tratamentos, cada um com quatro repetições, totalizando 16 unidades experimentais. As gaiolas $(0,80 \times 0,80 \times 1,0 \mathrm{~m})$ foram dispostas em um tanque de $8,0 \times 15,0 \times 1,5 \mathrm{~m}\left(180 \mathrm{~m}^{3}\right)$ com vazão de $300 \mathrm{~L} / \mathrm{h}$. Os animais experimentais foram medidos, pesados e posteriormente distribuídos homogeneamente ( $15,45 \pm 0,98 \mathrm{~cm}$ de comprimento e $43,5 \pm 2,2 \mathrm{~g}$ de peso), na densidade de 13 exemplares por unidade experimental, totalizando 208 exemplares.

Os parâmetros de desempenho avaliados foram: Ganho de peso (GP):

$$
\text { GP = Peso médio final }- \text { Peso médio inicial }
$$


Tabela 1 - Composição percentual das dietas experimentais

\begin{tabular}{lcrrr}
\hline Ingrediente (\%) & $\begin{array}{r}\text { Ração 1 } \\
\text { Controle }(\%)\end{array}$ & $\begin{array}{r}\text { Ração 2 } \\
(\%)\end{array}$ & $\begin{array}{r}\text { Ração } \\
(\%)\end{array}$ & $\begin{array}{r}\text { Ração } 4 \\
(\%)\end{array}$ \\
\hline Farinha de peixe & 27,00 & 27,00 & 27,00 & 27,00 \\
Protenose & 21,20 & 21,20 & 21,20 & 21,20 \\
Farelo de soja & 21,00 & 21,00 & 21,00 & 21,00 \\
Fubá de milho & 17,90 & 17,90 & 17,85 & 17,85 \\
Farinha de trigo & 5,05 & 5,00 & 5,00 & 5,00 \\
Óleo de soja & 7,00 & 7,00 & 7,00 & 6,95 \\
Suplemento & 0,80 & 0,80 & 0,80 & 0,80 \\
vitamínico e mineral ${ }^{1}$ & & & & \\
Vitamina C & 0,05 & 0,05 & 0,05 & 0,05 \\
Protease exógena & 0,00 & 0,05 & 0,10 & 0,15 \\
Total & 100,00 & 100,00 & 100,00 & 100,00 \\
Proteína bruta (PB) & 42,13 & 41,90 & 41,67 & 41,45 \\
ED (Kcal/100 g) & 479,80 & 477,26 & 474,77 & 472,27 \\
EB:PB, \% & 11,39 & 11,39 & 11,39 & 11,39 \\
\hline
\end{tabular}

${ }^{1}$ Suplemento vitamínico e mineral: P, 0,5\%; Cu, 2,66 mg; Fe, 16,66 mg; I, 0,25 mg; Mn, 25 mg; Zn, 16,6 mg; Vit. A, 3,33 UI; Vit. C, 1,000 ppm; Vit. $D_{3}, 800 \mathrm{UI}$; Vit. B, 10,46 mg; Vit. $B_{12}, 3,33 \mathrm{mg}$; Vit. $B_{2}, 1,66 \mathrm{mg}$; Vit. $\mathrm{K}, 0,52 \mathrm{mg}$.

Consumo médio de ração individual (CMDi):

$\mathrm{CMDi}=$ quantidade de ração fornecida por dia $(\mathrm{g}) / \mathrm{N}^{0}$ de peixes

Consumo individual médio de ração no final do experimento (CIMFi):

$$
C I M F i=\Sigma C M D i
$$

Conversão alimentar aparente (CAA):

$C A A=C I M F i$ / (peso médio final - peso médio inicial)

Crescimento específico em peso dos peixes (CEP):

$$
\begin{gathered}
C E P=100 \times(L n \text { peso médio final }- \text { Ln peso médio } \\
\text { inicial }) / \text { tempo }
\end{gathered}
$$

Taxa de sobrevivência dos peixes (TS):

TS $=100 \times$ (número final de peixes / número inicial de

$$
\text { peixes) }
$$

A homogeneidade do lote após pesagem no início do experimento foi analisada pelo teste Cochran a 5\% de probabilidade (Mendes, 1999). Os resultados das biometrias do experimento foram determinados por intermédio da análise de variância para o delineamento inteiramente casualizado, a 5\% de significância, com a finalidade de aferir o efeito dos tratamentos sobre o desempenho dos peixes. Quando "F" foi significativo, utilizou-se teste Tukey a 5\%.

\section{Resultados e Discussão}

A qualidade da água manteve-se estável durante todo o período experimental. Os parâmetros medidos durante os 55 dias do experimento foram: $\mathrm{pH} 5,5 \pm 0,3$; temperatura $27,8 \pm 1,0^{\circ} \mathrm{C}$; oxigênio $6,2 \pm 1,4 \mathrm{mg} / \mathrm{L}$; condutividade $24,0 \pm 2,3 \mu \mathrm{S} / \mathrm{cm}$; e amônia total $\left(\mathrm{NH}_{3}+\mathrm{NH}_{4}\right) 2,1 \times 10^{-3} \pm 10^{-3}$. Estes dados estão de acordo com os limites aceitáveis para cultivos confinados e, de certa forma, as estratégias de alimentação usadas neste estudo foram adequadas, visto que o monitoramento dos parâmetros físico-químicos da água (oxigênio, amônia, nitrito e temperatura) é prioritário para se definir a capacidade de suporte em cativeiro (Vinatea, 2004). Segundo Cole \& Boyd (1986), é possível que níveis críticos de amônia não ionizada interfiram negativamente no apetite e no crescimento dos peixes. Neste estudo os índices de amônia apresentaram oscilações mais evidentes no período vespertino, porém não influenciaram o desempenho zootécnico dos peixes do experimento.

A temperatura é o principal fator abiótico que influencia as taxas metabólicas em peixes, pois estes animais, por serem pecilotérmicos, diminuem o consumo de alimento, a taxa de alimentação, o tempo de evacuação gástrica e a atividade hidrolítica das enzimas digestivas (Smith, 1989; Soares \& Araújo-Lima, 2003). Não houve efeito da temperatura (média entre 26,8 e $28,8^{\circ} \mathrm{C}$ ) sobre a atividade da protease exógena, a exemplo do ocorrido nos estudos de Hidalgo et al. (1999). Tanto o pH como a condutividade elétrica da água mantiveram-se na faixa aceitável de variação no ciclo de 24 horas.

A atividade endógena das proteases ácidas e alcalinas observada neste estudo apresentou valores de 16,83 $\pm 1,62$ e $61,2 \pm 4,8 \mathrm{UI} / \mathrm{mg}$ de proteína, respectivamente, enquanto aquela obtida com pirarucus foi de 20,46 $\pm 2,45$ e 74,21 \pm $4,52 \mathrm{UI} / \mathrm{mg}$ de proteína (Cavero, 2004). Os valores da atividade da protease endógena em tucunarés, apesar de inferiores ao observado em pirarucus, foram superiores aos da atividade de proteases ácidas em carpas (Cyprinius carpio) (Hidalgo et al., 1999), o que, segundo esses autores, está relacionado ao tipo de trato digestório presente em carnívoros e onívoros. Em trabalhos realizados com "sea bass" (Lates calcifer) de hábito alimentar carnívoro e com "rabbitfish" (Siganus canaliculatus) de hábito alimentar onívoro, observou-se que as atividades das enzimas digestivas presentes no trato digestivo desses peixes dependem dos seus hábitos alimentares (Sabapathy \& Teo, 1993).

A exemplo do ocorrido nos experimentos de Cavero (2004), a atividade da protease exógena foi maior em $\mathrm{pH}$ ácido do que no $\mathrm{pH}$ alcalino para os juvenis de tucunaré, assim, a secreção de enzimas endógenas ocorre independentemente da suplementação enzimática. Portanto, a atividade da protease exógena apresentou efeito satisfatório no processo digestivo, agindo como complemento na digestão da dieta (Figura 1a, b e c).

O período de sete dias ao qual os tucunarés foram submetidos, em ambientes com iluminação reduzida de 50\% da intensidade externa, serviu para minimizar o estresse sofrido após a biometria inicial do experimento. Esta fase 
a

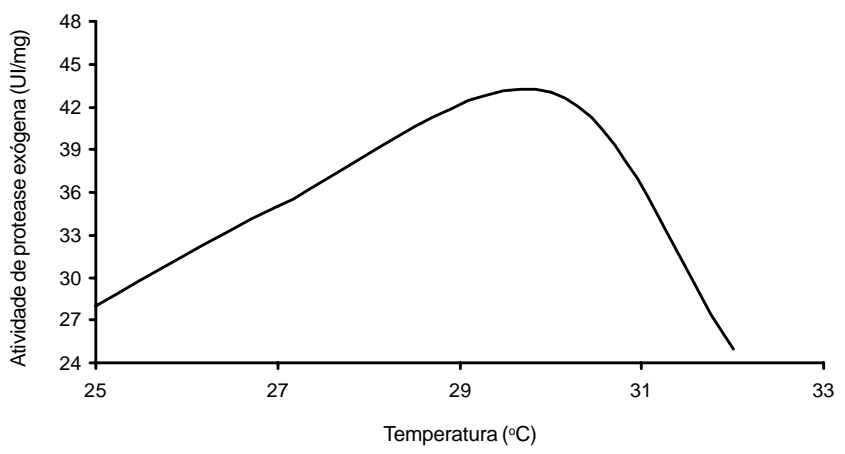

b

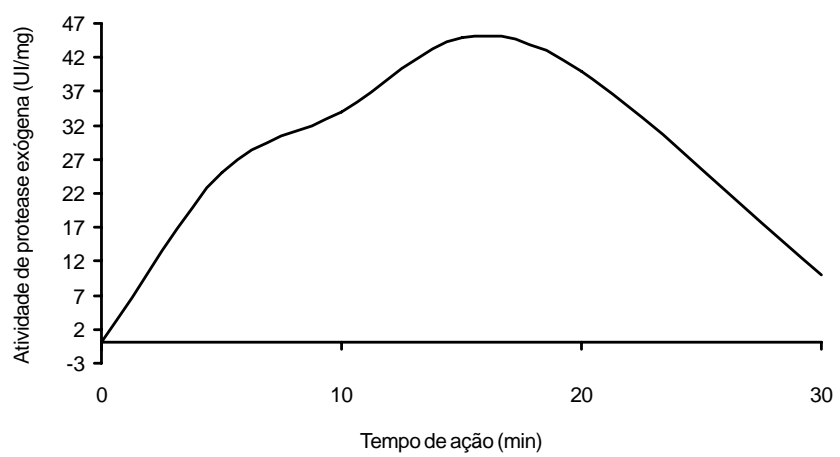

c

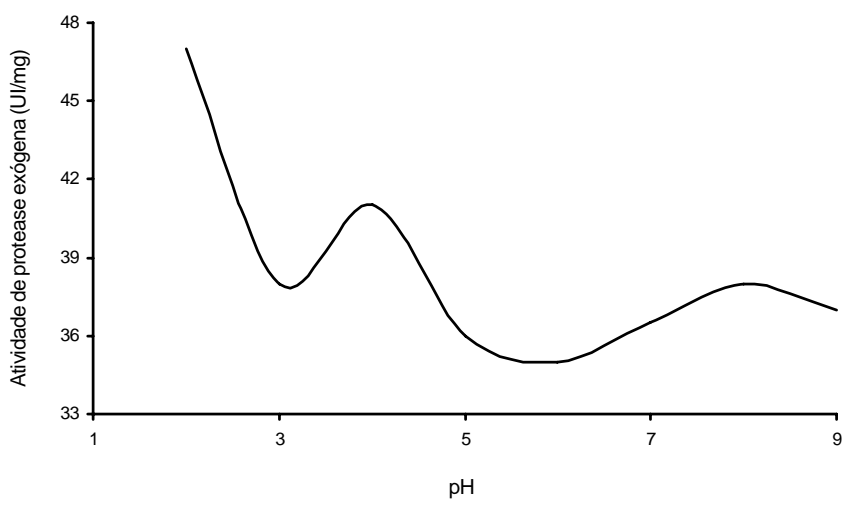

Figura 1 - Atividade da protease exógena em diferentes temperaturas (a), tempos (b) e pH (c).

preliminar foi necessária para evitar que valores de conversão alimentar fossem subestimados, em razão de alguns animais não estarem se alimentando regularmente. Segundo Soares \& Araújo-Lima (2003), a piranha-caju também necessitou de um período de 7 a 10 dias com iluminação reduzida para diminuição do estresse sofrido pelo transporte e pelos experimentos realizados com evacuação gástrica.

A farinha de peixe é a maior fonte de proteína dietética em rações para peixes (30 a 50\%) (Salum et al., 2002), por suprir a demanda de todos os aminoácidos exigidos por estes animais (Hardy, 1999; Pezzato, 2002) e possuir melhor palatabilidade (Webster et al., 2000), mas possuem suprimento limitado e custos elevados (Cheng et al., 2003). Isto sugere que fontes alternativas balanceadas sejam usadas na substituição da farinha de peixe na elaboração de dietas, sendo altamente recomendado por Francis et al. (2001). Segundo Webster et al. (2000), fontes de origem vegetal são mais baratas que de origem animal e, quando misturado com outros ingredientes, suprem a demanda exigida, proporcionando baixos custos e maior disponibilidade. Apesar de ser viável o balanceamento em dietas de proteínas de origem animal e vegetal, Burel et al. (1998) concluíram que ingredientes alternativos de origem vegetal possuem substâncias antinutricionais - termolábeis inibidores de proteases e lecitinas, antivitaminas, micotoxinas e alcalóides - que interferem no uso do alimento, afetando a saúde em peixes e, por conseguinte, limitando o percentual de inclusão destes ingredientes na formulação de dietas.

A solução é a adição de enzimas exógenas na formulação da dieta. Estudos realizados por Carter et al. (1997) comprovaram melhora no desempenho do salmão (Salmo salar), enquanto $\mathrm{Ng}$ et al. (2002) observaram a neutralização de antinutrientes e o aumento no valor nutritivo de farelo de palmeira para tilápia (Oreochromis niloticus). Cavero (2004) observou potencialização da digestão influenciando positivamente o ganho de peso de juvenis de pirarucus (Arapaima gigas).

Neste estudo, a inclusão de protease exógena na ração para tucunarés mostrou padrões de melhora na conversão alimentar, no ganho de peso e na taxa de crescimento específico para a espécie, a exemplo do ocorrido em experimentos conduzidos por Cavero (2004). Esta hipótese é bastante promissora, pois abre precedentes para diminuição de proteína animal (maior custo) nas dietas de carnívoros por dietas com proteína vegetal (mais baratas), adicionando-se enzimas, sem comprometer o desempenho zootécnico destas espécies. Segundo Tacon (1994), a alta demanda de proteína animal na dieta é um dos preceitos para impedir o desenvolvimento da piscicultura de carnívoros (Kikuchi, 1999).

O melhor índice de inclusão de protease exógena foi de $0,10 \%$, obtendo-se ganho de peso de $39,95 \pm 3,72 \mathrm{~g}$, conversão alimentar aparente de $1,93 \pm 0,13$ e taxa de crescimento específico em peso de $1,26 \%$ ao dia; os outros parâmetros analisados (consumo médio e diário individual de ração) não foram significativos (Tabela 2). Avaliando-se os resultados das outras três dietas, a ração com $0,10 \%$ de enzima teve rendimento médio 14,0; 17,0 e 22,0\% melhor em crescimento específico, ganho de peso e conversão alimentar 
Tabela 2 - Valores médios de peso inicial, peso final, ganho de peso, conversão alimentar aparente e taxa de crescimento específico de juvenis de tucunaré alimentados com dietas contendo inclusão de protease exógena

\begin{tabular}{lrrrr}
\hline & \multicolumn{4}{c}{$(\%)$ protease } \\
\cline { 2 - 5 } Variável & 0,00 & 0,05 & 0,10 & 0,15 \\
\hline Peso inicial & $45,5 \pm 2,45 \mathrm{a}$ & $43,4 \pm 2,54 \mathrm{a}$ & $41,58 \pm 2,13 \mathrm{a}$ & $43,91 \pm 2,04 \mathrm{a}$ \\
Peso final & $77,88 \pm 7,02 \mathrm{a}$ & $72,23 \pm 4,67 \mathrm{a}$ & $80,46 \pm 4,64 \mathrm{a}$ & $76,89 \pm 4,69 \mathrm{a}$ \\
Ganho de peso & $31,35 \pm 6,80 \mathrm{ab}$ & $28,82 \pm 2,46 \mathrm{~b}$ & $39,95 \pm 3,72 \mathrm{a}$ & $32,97 \pm 4,02 \mathrm{a}$ \\
Taxa de crescimento específico & $0,97 \pm 0,11 \mathrm{~b}$ & $0,91 \pm 0,14 \mathrm{~b}$ & $1,26 \pm 0,15 \mathrm{a}$ & $1,08 \pm 0,09 \mathrm{~b}$ \\
\hline
\end{tabular}

que o segundo melhor tratamento. Os dados obtidos nesta etapa experimental provavelmente teriam sido melhores, se, em vez de rações peletizadas, tivesse sido usado ração extrusada. Aksnes et al. (1997), avaliando a digestibilidade da proteína em dietas extrusadas e peletizadas, concluíram que as dietas peletizadas obtiveram rendimento $7 \%$ menor em relação às extrusadas. Segundo Kubtiza \& Cyrino (1997), rações peletizadas, embora tenham bom balanço nutricional, apresentam baixa estabilidade na água, possibilitando perdas que refletem em piores índices de conversão alimentar. Neste trabalho esta hipótese não foi testada, entretanto, em experimentos futuros, rações extrusadas suplementadas com protease devem ser testadas. Após a biometria final e a contagem dos indivíduos, foi observada sobrevivência de 97\% para os juvenis de tucunaré.

\section{Conclusões}

A inclusão de protease exógena melhora os índices de conversão alimentar, ganho de peso e crescimento específico para juvenis de tucunarés.

\section{Agradecimento}

À Fundação de Apoio à Pesquisa do Estado do Amazonas -FAPEAM e ao Instituto Nacional de Pesquisas da Amazônia - INPA.

\section{Literatura Citada}

AKSNES, A.; OPSTVEDT, J.; ANDERSON, J. Content of digestible energy in fish feed ingredients determined by-ingredient substitution method. Aquaculture, v.161, p.45-53, 1997.

BUREL, C.; BOUJARD, T.; CORRAZE, G. et al. Incorporation of high levels of extruded lupin in diets for rainbow trout (Oncorhyncus mykiss): nutritional value and effect on thyroid status. Aquaculture, v.161, p.325-345, 1998.

CARTER, D.J.; HOULINHAN, D.F.; BRECHIN, J. The relationships between protein intake and protein accretion, synthesis and retentiion efficiency for individual grass carps Ctenopharyngodon idella. Canadian Journal of Zoology, v.71, p.392-400, 1997.

CAVERO, B.A.S. Uso de enzimas digestivas exógenas na alimentação de juvenis de pirarucu (Arapaima gigas) (Cuvier, 1829). Manaus: Instituto Nacional de Pesquisas da Amazônia, 2004. 75p. Tese (Doutorado em Biologia de Água Doce e Pesca Interior) - Instituto Nacional de Pesquisas da Amazônia, 2004.

CHARLTON, P. Expanding enzyme application: higher aminoacid and energy values for vegetable proteins, In: Alltech Techinical Publications (Eds.) Biotechnology in the feed industry. Nottingham: Nottingham University Press, 1996. p.317-326.

CHENG, Z.J.; HARDY, R.W.; USRY, J.L. Effects of lysine suplemetation in plant protein-based diets on the performance of rainbow trout (Oncorhyncus mykiss) and apparent digestibility coeffcients of nutrients. Aquaculture, v.215, n.1-4, p.255$265,2003$.

COLE, B.A.; BOYD, C.E. Feeding rate, water quality, and channel catfish production in ponds. The Progressive Fish-Culturist, v.48, p.25-29, 1986.

FAO [2002]. The state of world of fisheries and aquaculture. Reports FAO information division. Disponível em: <http:// www.fao.org.> Acesso em: 22/8/2004.

FRANCIS, G.; MAKKAR, H.P.S.; BECKER, K. Antinutritional factors present in plant-derived alternate fish feed ingredients and their effects in fish. Aquaculture, v.199, p.197-227, 2001.

FUNGARO, M.H.P.; MACKHERONI JR., W. Recursos e melhoramentos genéticos para produção de enzimas utilizadas na indústria de alimentos. Jaguariúna: Embrapa Meio Ambiente, 2002. p.427-453.

GARUTTI, V. Piscicultura ecológica. São Paulo: Universidade Estadual Paulista, 2003. 332p.

HARDY, R.W. Aquaculture's rapid growth requirements for alternate protein sources. Feed Management, v.50, p.25-28, 1999.

HIDALGO, C.M.E.; UREA, A.S. Comparative study of digestive enzymes in fish with different nutrition habits. Proteolytic and amylase activities. Aquaculture, v.170, p.267-283, 1999.

KIKUSHI, K. Use of defatted soybean meal as a substitute for fish meal in diets of Japanese flounder (Paralichthys olivaceus). Aquaculture, v.179, p.3-11, 1999.

KUBITZA, F.; CYRINO, J.E.P. Feed training strategies for the piscivorous peacock bass Cichla spp. In: INTERNATIONAL SYMPOSIUM BIOLOGY OF TROPICAL FISHES, 1997, Manaus. Proceedings... Manaus: Instituto Nacional de Pesquisas da Amazônia, 1997. p.139.

KUBITZA, F. Nutrição e alimentação de tilápias - parte I. Panorama da Aquicultura, v.2, n.52, p.42-50, 1999.

MENDES, P.P. Estatística aplicada à aquicultura. Recife: Bargaço, 1999. 265p.

NG, W.K.; LIM, H.A.; LIM, S.L. et al. Nutritive value of palme kernel meal pretreated with enzyme or fermented with Trichoderma koningii as na dietary ingredient for red hybrid tilapia (Oreochromis sp.). Aquaculture Reseach, v.33, p.1199-1207, 2002.

PEZZATO, L.E. Alimentos convencionais e não-convencionais disponíveis para a indústria da nutrição de peixes no Brasil. In: SIMPÓSIO INTERNACIONAL SOBRE NUTRIÇÃO DE PEIXES E CRUSTÁCEOS, 1., 1995, Campos do Jordão. Anais... Campos do Jordão, 1995. p.34-52.

PEZZATO, L.E. Qualidade dos ingredientes, processamento e eficiência alimentar em aqüicultura. In: SIMPÓSIO BRASILEIRO DE AQUICULTURA, 2002, Goiânia. Anais... Goiânia: INBRAQ, 2002. p.224-229. 
SABAPATHY, U.; TEO, H. A quantitative study a saw digestive enzymes in the rabbitfish (Siiganus canaliculatus) and the seabass (Lates calcifer). Journal of Fish Biology, v.42, n.4, p.595-602, 1993.

SALUM, W.B.; BERTECHINI, A.G.; CANTELMO, O.A.; PEZZATO, L.E. Coeficiente de digestibilidade aparente da matéria seca, proteína bruta e extrato etéreo de ingredientes de ração para o matrinxã (Brycon cephalus) (GUNTHER, 1869) (Teleotei, Characidae). Ciência Agrotécnica, v.26, p.174-181, 2002.

SHEPPY, C. The current feed enzyme market and likely trends. In: BEDFORD, M.; PATRIDGE, G. (Eds.) Enzymes in farm animal nutrition finnfeeds international. Marlborough: Wiltshire, 2001. p.1-10.

SMITH, R.R. Nutritional energetics. In: HALVER, J.E. (Ed.). Fish nutrition. San Diego: Academic Press, 1989. p.2-31.

SOARES, E.C.S.; ARAÚJO-LIMA, C.A.R.M. Influência do tipo do alimento e da temperatura na evacuação gástrica da piranha caju (Pygocentrus nattereri) em condições experimentais. Acta Amazônica, v.33, n.1, p.145-156, 2003.
TACON, A.J.G. Feed ingredients for carnivorous fish species: alternate to fishmeal and other fisheries resources. Rome: FAO, 1994. v.881, 35p. (Fisheries Circular).

TORAL, F.L.B.; FURLAN, C.A.; SCAPINELLO, C. Digestibilidade de duas fontes de amido e atividade enzimática em coelhos de 35 e 45 dias de idade. Revista Brasileira de Zootecnia, v.31, n.3, p.1434-1441, 2002 .

VINATEA, A.L. Princípios químicos de qualidade da água em aqüicultura. 2.ed. Florianópolis: Universidade Federal de Santa Catarina, 2004. 231p.

WEBSTER, C.D.; THOMPSON, K.R.; MORGAN, A.M. et al Feeding frequency, affects growth, not fillet composition, of juvenile sushine bass Morone Chrysops x M. Saxatilis grow in cages. Journal of the Aquaculture Society, v.32, n.1, p.7988,2000

WORTHINGTON ENZYME MANUAL. Enzyme, enzyme reagents, related, biochemicals. Freshold: Worthington Biochemical Corporation 1982. 215p. 